\title{
Paradoxical hypoperfusion suggesting early and severe coronary dysfunction in tako-tsubo disease
}

\author{
Federico Ferrando-Castagnetto*1, Rodrigo Díaz ${ }^{1}$, Alejandro Vidal ${ }^{1}$, Roberto Ricca-Mallada ${ }^{1}$, Mariela Lujambio ${ }^{2}$, \\ Rodolfo Ferrando ${ }^{2}$ \\ ${ }^{1}$ Cardiology Department, University Cardiovascular Center, Facultad de Medicina, Universidad de la República, Montevideo, \\ Uruguay \\ ${ }^{2}$ Nuclear Medicine and Molecular Imaging Center, Facultad de Medicina, Universidad de la República, Montevideo, Uruguay
}

Received: November 18, 2016

Accepted: December 7, 2016

Online Published: December 14, 2016

DOI: $10.5430 /$ crim.v4n2p1

URL: http://dx.doi.org/10.5430/crim.v4n2p1

\begin{abstract}
Tako-tsubo disease (TD) is an unusual and paradigmatic clinical entity of unknown pathophysiology characterized by acute apical dysfunction usually triggered by physical or emotional stress. We describe the case of a woman with TD presenting early myocardial perfusion defects with transient dilatation and systolic dysfunction of left ventricle in gated-SPECT myocardial perfusion imaging, discussing the more likely mechanisms suggested by these functional findings.
\end{abstract}

Key Words: Hypoperfusion, Coronary dysfunction, Tako-tsubo

\section{INTRODUCTION}

Tako-tsubo disease (TD) is a paradigmatic clinical entity characterized by acute left ventricular (LV) dysfunction with apical hypo/akinesia that is usually triggered by physical or emotional stress. Although pathogenesis of TD has not been fully elucidated, extensive coronary spasm, catecholaminergic neurotoxicity and microvascular dysfunction has been defined as the most likely mechanisms. ${ }^{[1]}$

We report the case of a woman with TD exhibiting extensive perfusion defects with transient dilatation and systolic dysfunction of LV in gated-SPECT myocardial perfusion imaging (MPI), discussing potential underlying mechanisms suggested by these functional findings.

\section{Clinichl SCEnARIO AND IMAging}

A 66-year-old hypertensive woman with a hip prosthesis was derived to ${ }^{99 \mathrm{~m}}$ Tc gated-SPECT MPI (two-days stress-rest protocol) because of stable angina pectoris during last few months. No clinical, electrocardiographic (EKG) or imaging findings suggestive of myocardial ischemia or LV systolic dysfunction were observed after pharmacological stress (see Figure 1, panels A and C). Thereafter she remained asymptomatic and was discharged. During the night she suffered a stressful family event and immediately experienced chest pain, burning, which relieved spontaneously in 30 minutes. On next morning, in the Department of Nuclear Medicine, the patient repeated mild chest pain at rest. Cardiovascular physical examination: heart rate: $95 \mathrm{bpm}$, regular rhythm; normal S1 and S2, III/VI systolic murmur in mitral area without radiations; lung fields, no-rales. Surface EKG showed a slight ST-segment elevation through V3-V6, DI-aVL $(1.0 \mathrm{~mm}$ ) and type 2 Wellens' pattern (see Figure 1, panel B). Resting MPI revealed a large and intense perfusion defect extending through anterior, apical and lateral regions

\footnotetext{
*Correspondence: Federico Ferrando-Castagnetto, MD; Email: federico.ferrando@gmail.com; Address: Cardiology Department, University Cardiovascular Center, Facultad de Medicina, Universidad de la República, Montevideo, Uruguay.
} 
(paradoxical), transient dilation and decreased LV ejection fraction (LVEF) (see Figure 1, panel D). Plasma troponin I level: $0.68 \mathrm{ng} / \mathrm{ml}$. No coronary epicardial stenosis was found on coronary angiography (see Figure 2A). LV contrast ventriculography is illustrated in Figure $2 \mathrm{~B}$. Transthoracic Doppler echocardiogram performed 36 hours after admission: LVEF, 45\% (Simpson's rule); septal thickness, $14 \mathrm{~mm}$; dyskinetic septal-anterior and mid-apical segments; systolic anterior movement of mitral valve with mild regurgitation; dagger shape continuous Doppler signal in LV outflow tract ( 5 chambers apical view); peak transaortic pressure gradient increasing from 60 to $71 \mathrm{mmHg}$ during Valsalva maneuver. Cardiac magnetic resonance imaging (MRI) on sixth day of hospitalization showed an LVEF of $45 \%$; hypokinetic midapical and postero-lateral segments of the LV and mild left atrial dilatation. In addition, no signs of oedema, perfusion defects or presence of late enhancement were found (see Figure 2, panels $\mathrm{C}$ and D).
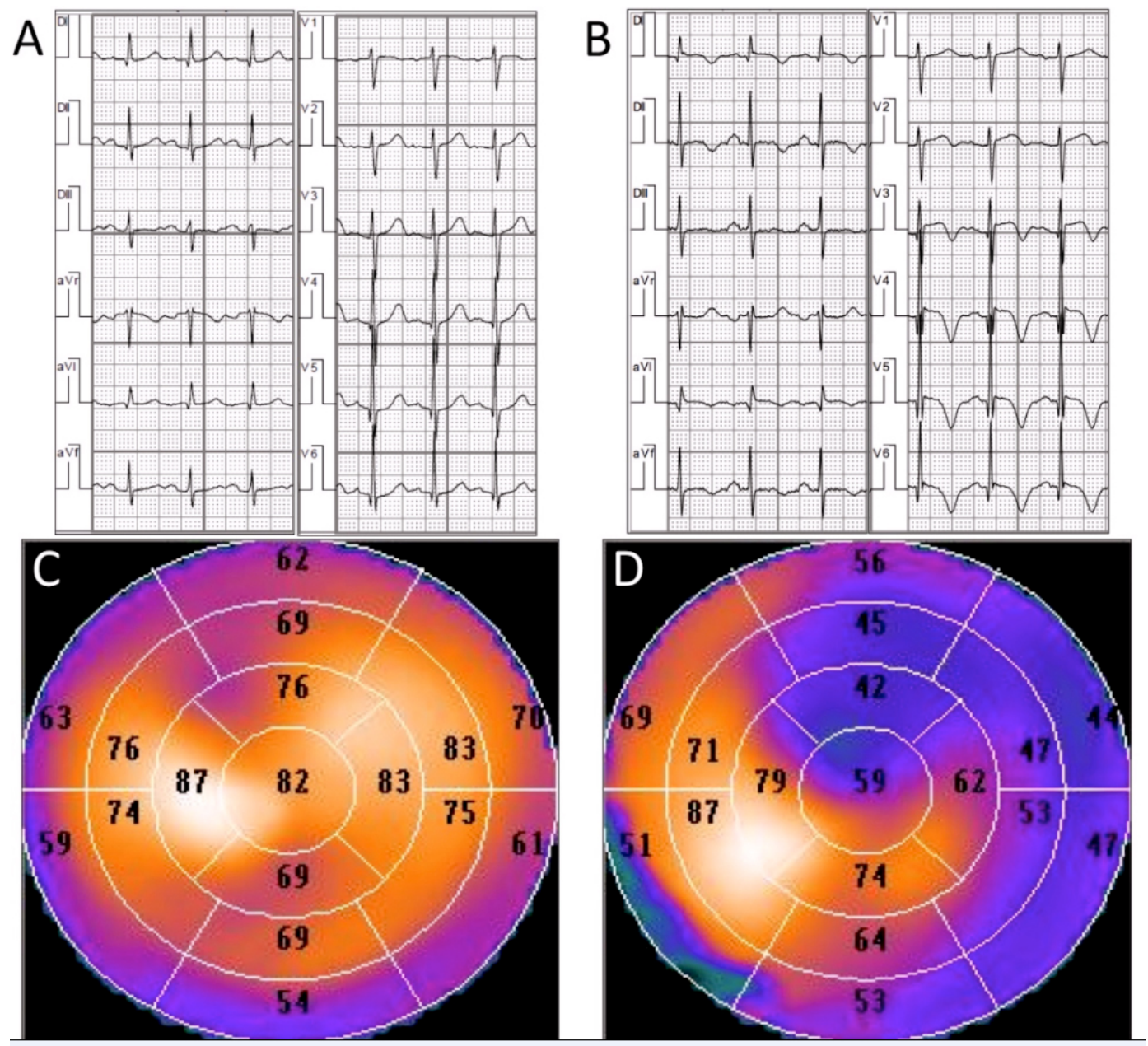

Figure 1. EKG and gated-SPECT abnormalities. A: 12-lead electrocardiogram (EKG) obtained in gated-SPECT protocol after dipyridamole. Previous (basal) EKG-record was identical; B: 12-lead EKG obtained immediately prior to rest gated-SPECT imaging, in the presence of angina showed: $95 \mathrm{cpm}$ sinus rhythm, $1.0 \mathrm{~mm}$ ST-segment elevation in DI-aVL $(1.0 \mathrm{~mm})$ and type 2 Wellens' pattern; normal corrected QT interval; C and D: Gated-SPECT 17 segment polar maps ("bull's eye") obtained during post-stress (C) and at rest (D). Paradoxical intense defect involving segments 1, 5, 6, 7, 11, 12, 13 and 17 with basal-diaphragmatic extension (segment 4). End-systolic left ventricular diameter was $12 \mathrm{ml}$ at post-stress and $65 \mathrm{ml}$ at rest.

In-hospital psychiatric evaluation found an ostensibly disturbed patient with no signs of depression reporting an acute stressful event during a family situation only 12 hours before the SPECT image at rest (imprisonment of her daughter in a penitentiary). During follow-up she remained asymptomatic and normotensive under enalapril and amlodipine; EKG and transthoracic echo-Doppler were normal. A new MPI performed 3 months after discharge showed normal perfusion, cavity volumes and systolic function of $\mathrm{LV}$, both at rest and post-stress. 

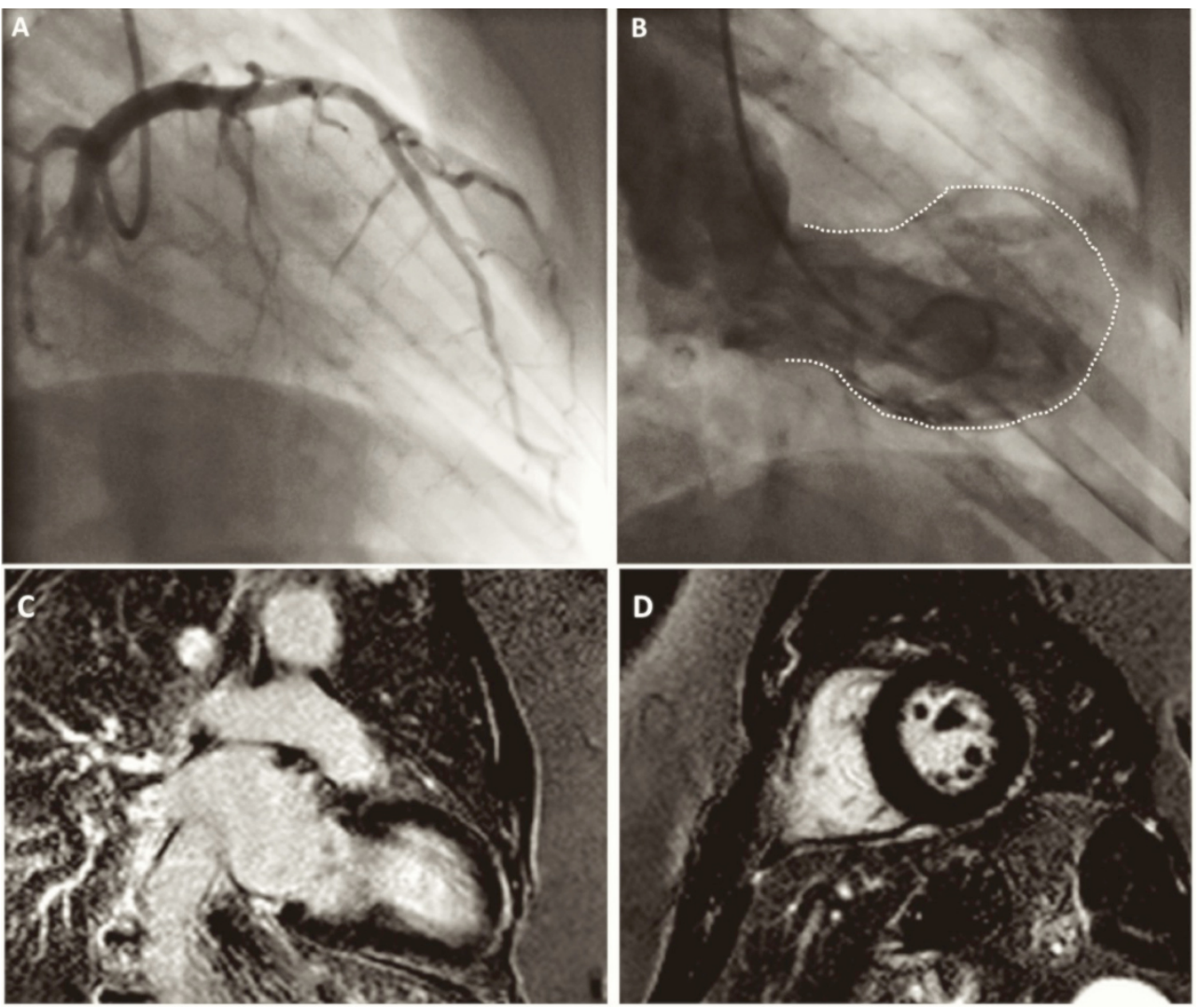

Figure 2. In-hospital coronary angiography and cardiac MRI. A: Left coronary angiogram: absence of significant epicardial stenosis; B: Contrast left ventriculograhy at end-systole: slightly dilated LV cavity, mid-basal hipomotilty and basal hypermotility. Dotted line shows tako-tsubo like LV shape. Intraventricular peak-to-peak gradient: $60 \mathrm{mmHg}$; $\mathrm{C}$ and D: T1 inversion-recovery late-enhancement sequences in cardiac MRI confirmed the absence of pathological myocardial enhancement after six days of admission.

\section{DisCUSSION}

Diagnostic criteria of TD were fulfilled in this clinical setting, including the presence of transiently altered motility of LV apical and middle ventricular segments; absence of epicardial coronary disease, new EKG changes (deeply inverted T wave) and moderately elevated levels of cardiac troponin in the absence of pheochromocytoma or myocarditis. ${ }^{[2]}$ In large case series, individuals with TD generally present an anterior ST-segment elevation as first anomaly in EKG. ${ }^{[2,3]}$ In this case, Wellens' type 2 pattern emerged 12 hours after an acute stressful event. Early transthoracic Doppler echocardiography found severe LV systolic dysfunction, hypocontractility of mid-apical segments and increased contractility of basal segments. The presence of significant pressure gradients in LV outflow tract is an uncommon feature in TD, especially found in medium ventricular phenotypes. ${ }^{[3]}$ Additionally, the absence of intramyocardial oedema and fibrosis in MRI and normal LV perfusion in gated-SPECT during followup confirmed the reversibility of structural and functional abnormalities.
In light of available data, extensive (multivessel) coronary spasm, catecholaminergic neurotoxicity and microvascular dysfunction had been suggested as most likely mechanisms underlying tako-tsubo. ${ }^{[1,3]}$ However, these hypotheses are not mutually exclusive but in some ways complementary to each other. Coronary epicardial spasm has been linked to myocardial stunning in TD after demonstrating that this physiological phenomena could be induced by different stimuli. However, less than $30 \%$ of patients with TD exhibited coronary spasm during ergonovine provocative tests. ${ }^{[4]}$ On the other hand, acute coronary spasm is usually followed by ST-segment elevation in EKG, a finding closely correlating with an intense perfusion defect corresponding with a localized vascular territory in MPI. So, myocardial stunning involving several coronary artery territories argues against isolated vasoespasm theory. Finally, multivessel vasospasm in the absence of atherosclerotic lesions is very unusual and frequently resolves after nitroglycerine administration during angiography. Catecholamine-induced cardiotoxicity is another likely mechanism in TD..$^{[1,3,5-7]}$ A systemic hyperadrenergic state resulting from physical or emotional stress 
was suggested by highly elevated circulating catecholamines during the acute phase of TD, ${ }^{[5]}$ although a direct local effect of catecholamines on cardyomyocites associated with regional differences in adrenaline sensitive beta2-receptors from base to apex is contradicted by reports of systemically administered epinephrine and dobutamine inducing TD. ${ }^{[6,7]}$

Changes in myocardial perfusion have been characterized through ${ }^{99 \mathrm{~m}} \mathrm{Tc}$ gated-SPECT in patients with $\mathrm{TD},{ }^{[3,8,9]}$ demonstrating moderate/severe LV perfusion defects that typically reversed from the sub-acute phase to a greater extent than in patients with atherosclerotic acute coronary events. ${ }^{[9]}$ However, only a few isolated case reports could demonstrate an early hypoperfusion state in this clinical setting ${ }^{[8,10]}$ one of these during exercise testing. ${ }^{[11]}$ Although scarce, we think these imaging findings could provide new insights about TD pathophysiology. ${ }^{99 \mathrm{~m}} \mathrm{Tc}$ is a monovalent lipophilic cationic component binding to the mitochondrial apparatus of myocytes. Depending on cell membrane potential, this isotope is exclusively retained in viable myocardium and removed as a function of coronary blood flow. So, a significant decrease in ${ }^{99 \mathrm{~m}} \mathrm{Tc}$ uptake reflects a flow-dependent deficit in membrane function and/or an absence of mitochondrial membrane potential. ${ }^{[12]}$ In our clinical case, an early intense and fully reversible perfusion defect extending through more than one vascular territory suggest transient

\section{REFERENCES}

[1] Kurisu S, Kihara Y. Tako-tsubo cardiomyopathy: Clinical presentation and underlying mechanism. Journal of Cardiology. 2012; 60: 429-37. PMid:23078863 https://doi.org/10.1016/j.jjcc.2 012.06 .015

[2] Prasad A, Lerman A, Rihal CS. Apical ballooning syndrome (TakoTsubo or stress cardiomyopathy): A mimic of acute myocardial infarction. Am Heart J. 2008; 155: 408-17. PMid:18294473 https: //doi.org/10.1016/j.ahj. 2007.11.008

[3] Dorfman TA, Iskandrian AE. Takotsubo cardiomyopathy: state-ofthe-art review. J Nucl Cardiol. 2009; 16: 122-134. PMid:19152137 https://doi.org/10.1007/s12350-008-9015-3

[4] Gianni M, Dentali F, Grandi AM, et al. Apical ballooning syndrome or takotsubo cardiomyopathy: a systematic review. Eur Heart J. 2006; 27(13): 1523-9. PMid:16720686 https : //doi .org/10.1093/eu rheartj/ehl032

[5] Wittstein IS, Thiemann DR, Lima JA, et al. Neurohumoral features of myocardial stunning due to sudden emotional stress. N Engl J Med. 2005; 352(6): 539-48. PMid:15703419 https ://doi .org/ 10.1056/NEJMoa043046

[6] Abraham J, Mudd JO, Kapur NK, et al. Stress cardiomyopathy after intravenous administration of catecholamines and beta-receptor agonists. J Am Coll Cardiol. 2009; 53(15): 1320-5. PMid:19358948 https://doi.org/10.1016/j.jacc.2009.02.020

[7] Lyon AR, Rees PS, Prasad S, et al. Stress (Takotsubo) cardiomyopathy-a novel pathophysiological hypothesis to explain microvascular dysfunction as the main mechanisms involved in TD. Moreover, we think it is unlikely that these scintigraphic findings could be explained solely on the basis of beta2-adrenoreceptor-dependent cardiodepression without severely decreased coronary vascular reserve.

Since most structural and functional changes could be fully resolved even when the stressful situation is maintained, defining any causality associated with physical or emotional acute stress is clinically difficult in TD. Additionally, psychiatric and cognitive psychology researches exploring potential predisposing factors for TD are still limited. If some mental health disorders could really predispose a subpopulation of patients to the development or recurrence of TD, an investigation of psychosocial attributes, personality traits and chronic stress, and even a specialised early intervention may be warranted. Third updated universal definition of myocardial infarction describes this event as an acute myocardial injury with cellular death characterized by the presence of a compatible clinical and EKG scenario with elevated serum levels of specific biomarkers. With deeper comprehension about pathophysiology of TD, a more precise characterisation of type-2 acute myocardial infarction (secondary to ischaemic imbalance) will be required.

\section{CONFLicts OF InTEREST Disclosure}

The authors have declared no conflicts of interest. catecholamine-induced acute myocardial stunning. Nat Clin Pract Cardiovasc Med. 2008; 5(1): 22-9. PMid:18094670 https : //doi. org/10.1038/ncpcardio1066

[8] Akashi YJ, Takano M, Miyake F. Scintigraphic Imaging in TakoTsubo Cardiomyopathy. Herz. 2010; 35: 231-9. PMid:22086475 https://doi.org/10.1007/s00059-011-3445-4

[9] Ito K, Sugihara H, Katoh S, et al. Assessment of Takotsubo (ampulla) cardiomyopathy using ${ }^{99 \mathrm{~m}} \mathrm{Tc}$-tetrofosmin myocardial SPECTcomparison with acute coronary syndrome. Ann Nucl Med. 2003; 17 : 115-22. PMid:12790360 https://doi .org/10.1007/BF029884 49

[10] Koh AS, Kok H, Chua T, et al. Takotsubo cardiomyopathy following dipyridamole pharmacologic stress. Ann Nucl Med. 2010; 24: 497500. PMid:20340053 https://doi .org/10.1007/s12149-010 $-0371-0$

[11] Dorfman T, Aqel R, Allred J, et al. Takotsubo cardiomyopathy induced by treadmill exercise testing: an insight into the pathophysiology of transient left ventricular apical (or midventricular) ballooning in the absence of obstructive coronary artery disease. J Am Coll Cardiol. 2007; 49(11): 1223-5. PMid:17367668 https : //doi.org/10.1016/j.jacc.2006.12.033

[12] Watson DD, Glover DK. Overview of kinetic and modelling. In: Zaret BL, Beller G (eds.). Clinical Nuclar cardiology: State of the art and future directions. 3rd ed, Elsevier Pub, Philadelphia, Pennsylvania. 2005: 3-11. 